\title{
Meta-Analysis of Studies on Cause and Effects of Runaway Girls in Iran
}

\author{
Leila Zaer \\ Iran Rudehen Azad University M.A Graduated in Social Science Research \\ Email: Leila.Zaer@Yahoo.com \\ Mousa Khedmatgozar Khoshdel
}

Ph. D Candidate of Sociology, University of Isfahan, Isfahan, Iran

Email:MKhoshdel55@Gmail.com

Doi:10.5901/mjss.2014.v5n23p2006

\section{Abstract}

At the first look, Girls running away from home seems to be personal issue but according to its effects on social order it is the basis of many abnormal social behaviors such as prostitution, alcoholic and narcotic addiction, drug distribution, organizing of gangs, deceiving other women and girls, spreading prostitution, out breaking of sexual diseases and... . It also expose them to the serious mental and physical disorders and if we couldn't solve this problem, we will lose part of work and production force and mental \& physical health of considerable amount of future mothers of society. Method of this study is Meta-analysis and consider 26 essays on runaway girls. In the beginning questions from previous studies were asked and then we compared findings and researches. Then we descriptively analyzed the quantity of previous researches and also analyzed the quality of basic concepts and relation between variables. Results showed that there is a meaningful relation between occurrence of girls running from their homes and variables such as age, previous record, marital status, narcotic addiction, interpersonal relation problems, parents' life style, mental or physical abuse by parents or other members of family, presence of punishment without acclaim, social confidence, economic situation, modelling from groups and having sexual relations.

Keywords: Runaway girls, family structure, demographic factors, social-cultural structure, Meta-analysis

\section{Introduction}

According to the World Health Organization, each year more than one million adolescent aged 12 to 19 have ran away from their homes. For girls, only in the United States in 1998, over 600 thousand attempted to ran away ( Ardalan , 2003 : 2 ). In spite of the lack of reliable data in Iran, it appears that the incidence of the phenomenon of runaway girls has increased. According to available statistics, the number of girls in 1999 compared to 1986 increased by approximately $20 \%$. Other figures showed that in addition to this increase, the average age of this vulnerable group is reduced, so that the average age of runaways in 1999 reached to 17 and in 2000 to 14/7 (Farokhi, $2004: 10)$. Increasing number of runaway girls besides being vulnerable and the cultural fabric of society that there is a specific look to this gender, reveals the need for more attention to this issue. Social insecurity and delinquency caused that the most of the girls in the first days after they left their family and home, are raped. The results of a study at the University of social Welfare Sciences shows that $18 \%$ of girls and $60 \%$ of them on the first day of the first week are being sexually molested (Daghagheleh and Kalhor, 2010: 174).

Also, according to the Public Relation of State Welfare Organization of Iran , Statistics of runaways each year increase about $15 \%$, and many of the girls are relegated to welfare centers were introduced by police and a few of them are surrendered. According to some experts' findings, $60 \%$ to $80 \%$ of runaways will become prostitutes if they have not been collected by police force or welfare patrol, in addition to Social Consequences of the phenomenon of the runaways, mainly these girls are suffering from various kinds of mental illness and become aggressive; with negative perceptions of the environment, trying to get their revenge from the community, and subsequently many STDs such as AIDS and other social disorders, will be plagued society ( mirzaee , 2004 ). The significant point is that becoming prostitute of lots of girls and women in Iran in comparison with other countries, according to family norms, religious and social norms in particular, is considered a major social disorder.

This study has considered the following four main objectives:

A) Identify the demographic factors affecting girls running away from home ; 
B) Identify psychological-personality factors affecting girls running away from home ;

C) Identify family factors affecting girls running away from home ;

D) Identify socio-cultural factors affecting girls running away from home

\section{Literature Review and Theoretical Framework}

In researches, the factors affecting girls running away from home, have been considered from different approaches and different divisions offered for it.

A) Motivational approach

- $\quad$ Escape from: escape from problems such as family or school, these girls have problems in their home that are not solvable for them and eventually they couldn't bear and run away from home .

- Escape to: Escape to reach a romantic relationship, excursion and so on. This group felt indifference towards their families. This group also called "pleasure seeker".

B) Personality approach

Personality approach consider Characteristics as an explanation for behavior to run away from home that even running away is a " sign of neurosis " or relationship "between internal and external control " of running away relies on it. The purpose of "the absence of external control," is the inability to influence external events or withstand them. In addition by "lack of internal control " we means: motivational behaviors, anger, inability to judge and frustration (Sharlin and Morbarak, 1992 : 382)

- In Attachment theory, you will find a good social adaptation if individuals initial attachment to their caregivers is associated with feelings of safety . Lack of attachment causes a person to feel alone and anxious ( lajavardi, 2004: 115-114)

C) Social approach

- Schaffner in a research entitled " seeking relationship : new perspective for runaway adolescents", believes that the cause of adolescents escaping and diversion is weak emotional ties with the community . He cited the social bond theory and the commitment theory and holds that social commitment is broken in running away from home. But despite this fragmentariness, adolescents seem to resist against running away from home and it is their last choice for them. They try not to react against violence or conflict between their parents and not to break the rules of family and prefer to keep the Family. But for adolescents who have family problems, running away is last resort response (Schaffner , $1998: 619)$

D) Social deviance approach

Behaviors or situations that take away from the norm, are deviance. Deviance lies in inappropriate socialization and limited opportunities, pressure, access to abnormal ways, evacuation of excitement and role models are misleading (Robington, Weinberg,: 5-104). Durkim believes that the cause of all abnormal behaviors is in the social environment and deviance increases group cohesion (Momtaz, 2002: 59-58)

E) Labeling theory

This perspective focuses on situations in which problematic or deviant behaviors or situations are considered. Cause of social problems is eventually people's attention or social control factors to the issue. When a person or situation is labeled, the one who puts label usually takes advantage of such case. The major outcome of successful labeling is development of Deviance (secondary Deviance) and the expected continuation of violation. Suggested solutions for labeling approach are evolution in definitions and eliminating the use of labeling (Ibid: 138-137)

In Merton's opinion, deep gap between objectives and the means to achieve them, and as a result feeling of deprivation cause weakens of commitments toward goals and equipment and locate a man in the anomaly condition ( Aghabakhshi , $1999: 34-33$ )

Howard Becker believes that the basis of all cause of all deviances is within the social environment. Virton mentioned the importance of social pressure (family environment or accidental environment that determine intellectual value of youth) (Mohammadi , 2004: 32-31)

- Gary and Cataleh also know the society responsible for crime occurrence (Aghabakhshi, 1999: 29). In nonorganizational view of family by Tumas and Zenaniky if a man in a family found no restriction toward his personal willing this willing express normally and if he confront aversion hostile and antisocial behavior will be inevitable (Robington, Weinberg , $2003: 60-58$ )

F) Cultural approach

- in theory of cultural transmission, Sutherland says some social environments are often encourages illegal 
activities , while other areas don't and in fact, the term " bad friend " appears ( Giddens , Sabouri's translation , $2009: 140$ )

- Deman and his colleagues have shown that adolescents (girls and boys) with a little confidence and believe in "fate " and " fortune "who faced negative life events were more tended to anomie (Deman et al, 1993)

In social control theory, Hirshi believes deviance occurred when the link between individual and society is weak or broken, and if individuals are less committed and involved, their link with society is weaker and probability of deviance will increase (Momtaz:119)

Nie believes that family through direct and indirect internal surveillance, monitoring and satisfying its needs strengthened social ties. Individuals have no Conformity with society problem begins in the family, continues at school and ends in society (Ibid: 122).

\section{Methodology}

Meta-Analysis is a set of statistical methods for integrating the results of experimental and correlational studies that have been conducted independently and in conjunction with a single topic. Unlike traditional research methods, data examined in meta-analysis method comes from statistical summaries derived from independent studies. Therefore, meta-analysis combining data from several research to produce a single outcome ( Sharifi and colleagues , 2004: 299)

All the articles in the Scientific Information Database about "Runaway Girls" that has been archived, published from 2000 to 2011. In this study, about 26 articles that 14 of them are about social, cultural and family factors about runaway girls, and 12 other papers are about personality traits and psychological effects of Runaways has been discussed.

Analysis of the phenomenon of runaway girls in Tehran requires detailed information and statistics on which basis we can analyze and evaluate phenomenon. Unfortunately, obtaining this statistics is impossible for two reasons, first that, unfortunately there is no certain institution responsible for producing, storing and recording information, secondly, sometimes in some institutions, according to social view information considered confidential and it is difficult or impossible to access. This makes research conducting difficult. With presence of these problems by using of statistics gained from organizations responsible for recording data, we give analysis of this phenomenon in recent 10 years.

Table 1. Statistics about girls and women running away from home (identified by police)

\begin{tabular}{|c|c|c|c|c|c|}
\hline \multicolumn{3}{|c|}{$\begin{array}{c}\text { Statistics of young girls and women and children running away from their } \\
\text { home in Tehran Province (identified by police) }\end{array}$} & \multicolumn{3}{|c|}{$\begin{array}{c}\text { Statistics of young girls and women and children running away from } \\
\text { their home in Tehran (identified by police) }\end{array}$} \\
\hline Index & Number & Year & Index & Number & Year \\
\hline 100 & 331 & 1375 & 100 & 315 & 1375 \\
\hline 38 & 125 & 1376 & 36 & 112 & 1376 \\
\hline 164 & 542 & 1377 & 156 & 492 & 1377 \\
\hline 281 & 930 & 1378 & 284 & 894 & 1378 \\
\hline 149 & 494 & 1379 & 141 & 443 & 1379 \\
\hline 84 & 278 & 1380 & 76 & 240 & 1380 \\
\hline 145 & 481 & 1381 & 100 & 315 & 1381 \\
\hline 237 & 783 & 1382 & 175 & 552 & 1382 \\
\hline 232 & 767 & 1383 & 175 & 551 & 1383 \\
\hline 256 & 847 & 1384 & 174 & 548 & 1384 \\
\hline 330 & 1092 & 1385 & 270 & 852 & 1385 \\
\hline 187 & 618 & 1386 & 98 & 309 & 1386 \\
\hline
\end{tabular}

Source: police social department

\section{Findings}

The above statistics show that the statistics of runaway girls in recent 10 years has experienced different periods of increasing and decreasing trends. This statistics from 1997 to 1999 show the number of runaways in the police records. After that until 2001, the trend shows a declining trend, and again from 2001 to 2007, the trend has been upward. Here it is necessary to point out that the above figures represent individuals who have been arrested by the police, which could also be indicative of the police's policy. For example, at a time that police management is a more sensitive, more are 
detained and vice versa. Also during the last 10 years in Tehran province statistics of runaways grew and its growth index from 100 in 1996 reach to 200 in 2007. Although over the years the index has declined at times, but overall, the trend has been upward (Daghagheleh and Kalhor, 2010: 177)

\section{Demographic Analysis}

\subsection{Age}

As one of the variables effective in girls running away from home and its individual consequences in several studies, have different effects. So that in most investigations age variable mentioned under 20 years. In terms of demographic, evaluating results show that the age range of the sample group is 15 to 25 years. The average age of runaway girls is 18/46, with a standard deviation of 2/66 (Tehranizadeh et al, 2005; Rasoulzadeh et al , 2005; Zamani et al, 2012 ). Between the variable of age (mean 44/17) , and the risk of girls running away from home there is a meaningful relationship , according to research the higher the age among adolescent girls, they are more likely to escape from home , probably because they need less support from their parents and are seeking more independence ( shareh , 2008). The results of other research suggests that the majority of the runaways were aged under 20 years (Saki et al, 2007). In another study examining age range, subjects aged between 15 to 24 years, and the mean age was 17 years and 10 months. (Bazyari et al, 2003; Saberi et al , 2010; Shareh et al, 2005; Shareh and colleagues , 2006; Ardalan et al, 2002).

\subsection{Educational status}

According to the educational level of study cases which are mostly elementary and guidance school can indicate that there is inverse relationship between level of education and reducing crime. Because an individual having sufficient knowledge and information can choose the right path (Saki et al, 2007). about half of them have finished high school and the rest are illiterate or primary. ( Bazyari et al, 2003 ; Share and colleagues , 2007 ; Jamshidi et al , 2010; Tehranizadeh et al , 2005 ; Fathi , 2007 ; Rasoulzadeh et al , 2005 , Saberi et al, 2010). According to the result of the research conducted by Gharibi (2007) and Hashemi et al (2011) study and dropout problems in Runaways are more than normal girls.

\subsection{Record of running away}

Generally $36 \%$ of the study cases have one record of running away from home, 33 percent have tow or three and 31 percent of them have more than four records of running away (Hamidi, 2004). majority of subjects in this study (approximately 81\%) had a previous record of presenting and maintaining in the facility, arrest and imprisonment, record of previous run and multiple sexual relationships (Saki et al, 2007). About 60 percent of them had record of arrest, detention and rehabilitation (Bazyari et al, 2003). More than half of the runaway girls had record of escaping from their home (Fathi, 2007)

\subsection{Occupation}

About $92 \%$ of the study population are housewives (Saki et al, 2007)

\subsection{Marital status}

About $57 \%$ of runaways were married that half of them had forced to marry and mentioned this as a reason of their run and in some cases age difference with their husbands was the reason. It is noteworthy that about half of their husbands had addiction history, of 60 percent of them had history of imprisonment, and 58 percent had a history of committing fraud (Saki et al, 2007)

\subsection{Drug dependence}

In the research of Saki et al., among the addicts, 50\% had heroin addiction, 41 percent had opium addiction and about half of them used drug about 3 to 5 years. (Saki et al, 2007).in another study, about half of those smoking cigarettes and less than half of all runaways were using drugs (Bazyari et al, 2003). Approximately $35 \%$ of them before leaving 
home, had a history of addiction (Fathi, 2007). Also most of them lived in damaging environment and dealt with drug abuse and alcohol (Gray et al, 1998) and had a history of using drug and theft (Johnson et al, 2005; Saliou and et al, 2005).

\section{Evaluation of Information on Personality and Psychological Characteristics}

\subsection{Interpersonal problems}

As one of the effective variables in girls running away and its individual consequences, in several studies it has different effects. Findings showed that about $46 \%$ had phobia, $64 \%$ psychotic disorder, about $84 \%$ hypochondria, , $90 \%$ obsessive compulsive disorder; 82\% depression, 85\% pathological anxiety, $69 \%$ aggression, , $41 \%$ paranoid , and 56\% had difficulty in supporting interaction (Saki et al, 2007; Rasoulzadeh Tabatabai et al, 2005). Results showed that the highest frequency of tensions in runaways related to flee, commit Gilt, breaking relation with an old friend and ...., most of them feel lack of policy to deal with these tensions so they react emotionally instead of dealing with the problems and they escape (Bazyari et al, 2003; Moazzami Goudarzi et al, 2001). Subjects have low self-Esteem, not motivated and feel a little independence, have little family support and families are strict (Navabakhsh and colleagues, 2007). Was observed in findings that psychoneurosis is associated with increased risk of runaway girls, also the girls whose father was in the group with lower occupational status, are more likely to run (Jamshidi et al, 2010). According to researches, runaway girls are anxious (Rosenthal et al,2006) and hostile and have extrovert behavior (McGaha and colleagues,1995; Sherman et al 2005) and disorders and act with aggression (Ribeiro, 2008).

\subsection{Cognitive problems}

In study of Qulizadeh and colleagues, the results indicate that the Runaway girls and normal girls solve creative problems differently and there is a relation between personality and problem solving are related in Runaways (qulizdeh et al, 2007). generally, the results of Cattell's personality test, showed that runaway girls in comparison to normal girls is because of low intelligence, minor psychiatric, obedience and submission to others, emotional sensitivity, mistrust and self-sufficiency (Rasoulzadeh Tabatabai et al, 2005).

\subsection{Emotional-Personality Problems}

The results of the research done by Ahadi and Lotfi, stating that the two runaway girls and normal in Hypochondriasis, denial, interpersonal problems, anxiety, inferiority complex ,deviation, there is a significant difference, in other words the girls ( runaways) seriously have confused thinking organization and found differences between themselves and others (Ahadi and colleagues, 2007). According to Zargar et al study, the scale scores for interpersonal sensitivity, depression, anxiety, paranoid thinking, there was significant difference between Runaways and normal girls (Zargar et al. 2008; Shareh et al, 2005). According to Hashmi and others observation (1390), depression, self-mutilation, and suicide were seen in runaway girls. Also, according to research conducted runaways are depressed (Booth and colleagues, 1999; Ayerst, 1999) and have suicidal thoughts and attempts (Lewis, 1991) and have low self-esteem (Spirito and colleagues, 2006; Leslie et al, 2002 ).

\subsection{Identity}

Average scores for identity base for Runaways with Average scores for ordinary girls have meaningful difference. In other words, running away from home in adolescence could lead to scattered identity and increase the individual problems (Shareh and colleagues, 2007). Research results show that there is a difference among adolescents (boys \& girls) facing problems due to the different social roles. These roles come with great emphasis on autonomy for boys and attachment and relation for girls is (Frydenberg, 1997; Boldero and Fallon, 1995; Zemmerman et al, 1997).

\section{Analyzing Information of Family Structure}

\subsection{Function and structure of family}

Runaway girls usually come from families with inappropriate structure in society, so their families had difficulties in 
"problem solving" also have lower functionality in "family roles", "problem solving "and" emotional performance" than the norm of society.in These families often chaotic power structure forms, so that one parent has all the power, or because parents have stepped down from the role, children take control of the situation, So the family had difficulty in "problem solving" (Hamidi et al, 2004; Hamidi, 2004). Results showed that between runaway girls and normal group there was significant differences in four of five dimensions of family cohesion scale (the dimensions of solidarity with father, marital relationship of parents, the location of interactions, parents Relations with children). The findings suggest that the relationships between parents and parents with children are important predictor in distinction of runaways from normal girls (Samani, 2006). Family breakdown such as parental divorce, addiction, prison history, differences, disputes and conflicts between family members of runaways are more common than homogenous groups (Fathi, 2007). Aghamohammadi and his colleagues in a research, by teaching efficacy to runaways, increase and improve social relationships and social interactions of them (Aghamohammadi et al, 2011).

\subsection{Parental Status}

More than half of the parents of the runaways (59\%) have lived apart e (Hamidi, 2004). approximately $35 \%$ of the parents of the runaways were separated. Also, about 66 percent of their fathers had primary and secondary levels of education, and 35 percent of their mothers had primary education (rasoulzadeh Tabatabai, et al, 2005). Approximately $44 \%$ of runaways live with one parent and $32 \%$ of those live with someone else (Fathi, 2007). Highest level of education for fathers of runaways was middle school, and elementary school for their mothers (Saberi et al, 2010).

\subsection{Physical and mental abuse by their parents or other family members}

More than half of the runaways (67\%), afraid of one of their family members. Usually reason of fear in half of them is their father and in others, the family members (Hamidi, 2004).almost half of the girls mentioned the fierce clashes and conflicts with their parents, poor interpersonal relations between parents and children, and the parents were often illiterate (Saki et al. 2007). Runaways experienced More Physical abuse, beatings, humiliation, and insult than their counterparts from their parents. In addition, in the item of violence experience, runaways harassed by their siblings more than normal girls (kamrani fakour, 2006). Results showed that runaways have dysfunctional attitudes and receive more verbal and physical violence than ordinary girls (imanifard and colleagues, 2010; Gholizdeh and et al, 2007). 42\% of runaways reported that in their life their parents' were indifference toward them, $36 \%$ of them regularly had problems with their parents had, and about half of them had no feelings to their families (rasoulzadeh Tabatabai, et al, 2005). Half of Runaways believed that sometimes physically harassed by supervisors and family members and more than half believed that they suffered from emotional abuse (Fathi, 2007; Gharibi, 2007; Hashemi et al, 2011). About 30\% of samples experienced physical abuse at home (from once to several times), those who abuse were family members in most cases (about 77\%) and others including stepfather, and stepmother (about 23\%) (Saberi et al, 2010). According to Bahrami and his research group, runaways in all components of abuse (neglect, emotional abuse, physical abuse, sexual abuse) showed significant difference from normal females (Bahrami and colleagues, 2007). Findings of this research are correspond with results of researches conducted by (Sappington, 2000; Whithback et al, 1997; Hatty et al, 1994; Tyler et al, 2004).

\subsection{Presence of punishment without encouragement}

$33 \%$ of runaways never encouraged at home and 84 percent have already been punished, of which $71 \%$ are physically punished (beaten and expelled from the house) and 29 percent experienced mental punishment (frown, breaking with, threatening to). $57 \%$ punished by father and 16 percent of them elder brother. $38 \%$ of fathers and 36 percent of mothers punished their children excessively (rasoulzadeh Tabatabai, et al, 2005).

\subsection{Population of family}

More than half of the runaways were from large families (up to six) (Hamidi, 2004).

\subsection{Relationship exists between the parents and having differences with them}

The Runaway girls witnessed far more violence, especially violence against their mothers than normal girls (kamrani fakour, 2006). 53 percent of parents of runaways have problems (rasoulzadeh Tabatabai, et al, 2005; Fathi, 2007 ; 
Gharibi, 2007). In researches conducted by Daly and Willson (2002), Sahin et al (2010) they found that most runaway adolescent physical abuse happened in a families that have seprated parents and have serious family problems.

\section{Analyzing Information on Social - Cultural Structure}

\subsection{Social trust}

According to the study of Zamani and colleagues (2012) on relationship between social trust of families and runaway girls; indicators of social trust and institutional trust between family members evaluated as low. Available data suggest that trust in social institutes between Runaways' families is low and in normal girls is average and few percentage of both have high institutional trust.

\subsection{Media}

About the use of mass media, respectively, $96 \%$ of runaways use TV, $75 \%$ of runaways use radio, and 85 percent of runaways use satellite (Saberi et al, 2010).also in study of Rasoulzade et al. (2005) TV 93\%, 46 percent radio and 70 percent of runaways use satellite.

\subsection{Economic conditions}

Average income of runaways' father and mother, respectively was, $4 / 5$ million Rials and 2/8 million Rials per month. The majority of runaways about 51 percent were lived alone (Saberi et al, 2010). Highest income of runaways' father has been reported between 50 and 100 thousand Tomans. Also there is a meaningful difference between runaways and normal girls in fulfillment of their needs, having personal house, and allowance (rasoulzadeh Tabatabai, et al, 2005).

\subsection{Role modeling from actors}

About half of runaway girls imitate from their favorite actor (Rasoulzadeh Tabatabai, et al, 2005).

\subsection{Role modeling from groups}

About half of the girls had been modeling from groups such as rap and heavy metal (Rasoulzadeh Tabatabai, et al, 2005).

\subsection{Having sexual relation}

History of sexual relationship with the opposite sex before running away existed about $34 \%$ in which the opposite sex (about 88 percent) were stranger, and in 12\% were relatives (Saberi et al, 2010). About 49 percent of girls had sex for survival after escape. Pregnancy outcomes in subjects with a history of sex for survival were intentional abortion about $82 \%$, about $23 \%$ of live births, and 1 abortion. (Ardalan et al, 2002). According to Gharibi's studies (2007), and Hashemi et al (2011) establishment of unsafe sexual relations and sexual abuse is more among runaways than normal girls. According to studies in the last decade, the rate of HIV infection due to unprotected sexual relations between homeless and runaways is 6-fold higher than those associated with the opposite sex. Also drug and alcohol usage and unwanted pregnancies due to misuse of the pill and condoms (about 35 to 45\%) is observed to a greater extent (Kennedy et al, 2012). 
Table 2. Factors affecting the formation of girls running away according to the variables studied

\begin{tabular}{|c|c|c|c|c|}
\hline Percentage & Frequency & Variables & $\begin{array}{c}\text { Factors Affecting the Formation of } \\
\text { Runaway Girls }\end{array}$ & \\
\hline 39 & 10 & age & \multirow{6}{*}{ Demographic Structure } & \multirow{6}{*}{1} \\
\hline 39 & 10 & Educational status & & \\
\hline 15 & 4 & Running away record & & \\
\hline 4 & 1 & occupation & & \\
\hline 4 & 1 & Marital status & & \\
\hline 12 & 3 & Drug addiction & & \\
\hline 23 & " & Interpersonal relation problems & \multirow{4}{*}{ Personality and Psychological Structure } & \multirow{4}{*}{2} \\
\hline 8 & 2 & Cognitive problems & & \\
\hline 12 & 3 & personality-emotional problems & & \\
\hline 4 & 1 & Identity & & \\
\hline 19 & 5 & Structure and function of family & \multirow{6}{*}{ Family Structure } & \multirow{6}{*}{3} \\
\hline 15 & 4 & Parent life status & & \\
\hline 42 & 11 & $\begin{array}{l}\text { Physical or mental abuse by family } \\
\text { members or parents }\end{array}$ & & \\
\hline 4 & 1 & Punishment without encouragement & & \\
\hline 4 & 1 & Population of family & & \\
\hline 15 & 4 & Parents relation with each other & & \\
\hline 4 & 1 & Social trust & \multirow{6}{*}{ Social - Cultural Structure } & \multirow{6}{*}{4} \\
\hline 8 & 2 & media & & \\
\hline 8 & 2 & Economic condition & & \\
\hline 4 & 1 & Role modeling from actors & & \\
\hline 4 & 1 & Role modeling from groups & & \\
\hline 15 & 4 & Having sexual relation & & \\
\hline
\end{tabular}

\section{Discussion and Conclusion}

In general it can be stated that the children and adolescents running away from home, is considered as a defense mechanism that children and adolescents due to the emancipation of the suffering of their home, ran to the street, but unlike their imaginations they encountered an unknown environment. In fact, the girls who ran away from home showed a reaction to stress-causing conditions within her home. (Lewis 1991)

\subsection{Individual consequences of runaway girls}

The vast majority of girls running away from home, happens while the girl have no plan for after her escape from the house and have no knowledge about the consequences. According to some of these girls, escaping is more harmful to themselves than their families. They quickly hooked on drugs, alcohol and illicit goods, prostitution and ... . Criminal gangs identify and attract the girls,and sexually, physicaly abused them. After committing these types of crimes and immorality feel self-loathing, guilt and pollution. On one hand they cannot go back to normal life, and on the other hand, some of them due to confusion caused by rape, commit a suicide (Hashemi et al, 2011).

\subsection{Family consequences of running away}

In this topic, family fragmentariness plays the most important role and Studies show that running away in the first stage is mainly due to turbulence. Running away occurs when adolescent has serious problems in family atmosphere with and cannot solve the problem within a family atmosphere. Among the most important consequences of girls running away from home in family, is occurrence of emotional and mental problems for family members, especially parents.

\subsection{Sociocultural consequences}

No credible official statistics, has led some experts not to comment explicitly on phenomenon of runaways, but increasing 
evidences in parks and public places, has created a lot of speculation about the dramatic increase in the number. Sometimes young people without previous decision, decides to escape and leaving their house without aim or purpose, stranded in the city and immediately arrested by police officers (danesh, 1993). Besides his family, and himself running away also have social consequences. Increase in problems such as: addiction, trafficking, prostitution, theft,, sexual diseases and infections are the most important issues for the community. Each of the mentioned problems in society creates numerous damages. In addition, the economic losses that the phenomenon of runaway girls bring on society should not be overlooked. Many people in various organizations such as the judiciary, police, welfare work in this issue and a lot of costs associated with it (Hashemi et al, 2011).in order to solve the problems related to this issue as a sociocultural problem not only we need planning but also we need proper actions to control its social effects, for example: The above research findings show that girls who have returned to their homes, without changing condition, and families don't have necessary skills to deal with these girls. In order to prevent abuse, insult, humiliate the girls and emotionally supporting them it is necessary to ensure the safety and health of the girl after returning home, and support girls that their families for whatever reason are not willing to accept them.

\section{Offers}

In any society, Institutions, have duties and responsibilities to protect and uphold the rights of citizens, but without the active participation of individuals, realizing of their rights would not be possible. Therefore, it is necessary for all those who related in any way to children and adolescents and any damages and problems relate to this group to be familiar with children's right:

At first, parental awareness of children's rights is necessary because the family is the most important base for children's growth and education and should be a safe and loving home for them. Findings indicate that families with high risk of running girls have suffered from unstable relationships, family conflicts and discrimination. Thus providing ongoing advice to families and tried to compile programs regularly and rebuilding the family is necessary.

-education of Child rights and parenting skills to parents in order to raise awareness to the needs of the various stages of child development and how they respond to it ;

- $\quad$ putting this issue on media and clarify the effecting factors on girls escaping from home and preventing cliché will be helpful

Second, it is essential that teachers, administrators, social workers and counselors in training centers, and welfare services who deal with children and young people know the rights of the child so he can help and teach them to the others. Based on the findings of this study, we can suggest to the social workers who are dealing with this issue that are as follow:

- Disseminate the culture of counseling and social services to strengthen family support networks, reduce conflict and domestic violence ;

- $\quad$ Requiring aggressive families to attend counseling sessions and parental skills training

- $\quad$ Providing counseling to runaways, emotional support to strengthen the relationship with the family of the girls and in some cases doing necessary legal actions to support the girls who live in traumatic.families

- Change the look of the community toward runaways, runaways are sacrifices of dysfunctional family and circumstances. This way of looking may be helpful and reduce the pressure that may eventually be able to return and help rehabilitate them .

- Design and develop Internet-based systems and telephone counseling to provide key training and providing necessary information for teenage girls who are intended to escape

- Develop a training program to strengthen specific components of emotional intelligence, stress and anger management training, education in order to raise self-esteem and happiness and educational programs to enhance problem-solving strategies, including practical solutions for women who are at serious risk for running away from home .

- Legally, running away is not considered as crime and it is a social problem so there is no specific law for this, but some of runaway girls have mental disorders that in judiciary it is not considered and after serving their sentence, the welfare organization found the problem and this issue requires further consideration.

- In addition, it is necessary that experts overcome challenges and shortcomings of law in this field to revise, and show flexibility therefore some points seems to be necessary to be mentioned:

- Review and amend existing legislation on children's rights and laws preventing corporal punishment and child abuse so that parents who commit child abuse, should be prosecuted ; 
- opening office of legal protection of children and youth in the justice courts with the necessary and appropriate authority to protect abused children is essential

- Lack of effective laws on child abuse and domestic violence and guardianship issues, are factors of increasing violence. Also the lack of effective law to prevent children's marriage and marriage unwillingly and inadequacy of policies to interfere in family crises increase the probable child abuse.

\section{References}

Aghabkhshy , H . (1999). Addiction and family pathology : approach to social working. Tehran : University of Welfare and Rehabilitation Sciences .

Aghamohammadi , S. , M. Bagherkajbaf, Neshatdoost Hamid Taher et al , (2011), The effects of training on self-efficacy and social relationships of runaways : a single case study, Journal of Clinical Psychology, Third Year, No. 2.

Ahadi, Hassan, Farah Lotfi Kashani (2007 ), Runaway and Normal Girls Personality Traits, applied psychology , first edition , No. 4.

Asfydvajany Saberi , M. , marzie molavi nojumi, sayyed kazem malakouti et al , (2010), Evaluation Of Frequency-Related Factors Of Runaways Referred To The Forensic Center Of Tehran Province , Journal of forensic, year 16, No. 1.

Ardalan, Ali . (2003). Examine the phenomenon of runaway girls and married women, University of Welfare and Rehabilitation Sciences

Ardalan , A. , K. Holakui Naini , Alireza Mohseni Tabrizi and colleagues (2002), Sex for survival : outcomes of girls running away from home, social welfare, Second Year, No. 5.

Ayerst, S. L. (1999). Depression And Stress In Street Youth. Adolescence. 135. 567-575.

Bahrami Ehsan, Hadi ; Sahar Tahbaz Hosseinzadeh, (2007), Comparison of Runaway girls and normal girls in Tehran, Tabriz University, Psychology, Second Year, No. 8.

Bazyari Meymandi , M , K. Rasoulzadeh Tabatabai, Azad Fallah P. , (2003), Comparative Study of Stress and Coping method of Runaways and normal girls in Tehran, Journal of Psychology, Year VII , No. 4.

Boldero, J. \& Fallon, B. (1995). Adolescent Help-Seeking: What Do They Get Help for and From Whom?, Journal of Adolescence. 18. 193-202.

Booth, R. E. and Zhang, Y. (1999). The Challenge of Changing Drug and Sex Risk Behaviors of Runaway and Homeless Adolescents. Child Abuse and Neglect. 23. 1295-1306.

Daghaqeleh , Aqeel, Samira Kalhor (2010). Urban damages in Tehran (Vandalism , runaways, women households, and begging). Tehran : Sociology.

Daly, M. Willson, M. (2002). Child Abuse And Othere Risks Of Not Living With Both Parents, Journal of Consulting and Clinical Psychology. 10(17). 285-288.

Danesh Tajzaman , (1993), Children and Juvenile Offenders, Tehran : Tehran Times Foundation.

Deman, A. F , et al. (1993). Correlate of Anomie in French Canadian Adolescents, The Journal of Social Psychology. Vol 133. № 2.

Fathi , M. , (2007 ) , Factors Of Girls Running Away From Home , social welfare, Issue 27.

Faroukhi , J. , (2004), Factors Affecting Girls Running Away From Home, MSc dissertation, shahid Beheshti University .

Frydenberg, E. (1997). Adolescent Coping, Theoretical and Research Perspectives, New York. Routledge.

Gary, F., Moorhead, J. and Warren, J. (1998). Characteristics of Troubled Youth in Shelter, Archives of Psychiatric Nursing. 10. 41-48.

Gharibi , H. , (2007) , Family And Cultural Factors Affecting Girls Running Away From Home , Applied Psychology , First edition, No. 4.

Giddens , Anthony (1999). Sociology, translated by Manouchehr Sabouri, Tehran : Ney publication.

Hamidi , F , (2004), The Impact of Families Structure on Runaway Girls , women's studies, phase 2, No. 3.

Hamidi , F, Afroz, G. , A. Kyamnsh et al. (2004) Analyzing the effect of family structure in Runaways and family therapy. psychology , No. 30.

Hashemi , Seyed Zia , Zeinab Fatemi Amin , M. Fuladyan , (2011), Implications Of Girls Running Away From Home, social welfare , Year XI, No. 40.

Hatty, S; Davis, N \& Burke, S. (1994). No Exit: Violence. Gender and the Streets. Australian Journal of Social Issues. Vol 24. No 4.

Imanyfard, E. , M. Kamkar, (2010), Comparison of Domestic Violence and Dysfunctional Attitudes in Runaways and Ordinary Girls , new findings in psychology, Fifth Year, No. 14 .

Johnson, W. R., Prestopink, J. L., \& Slesnick, N. (2005). Predictors of Aggression in Substance Abusing Adolescent Runaways, Center on alcoholism, substsnce abuse, and addictions (CASAA), University of New Mexico.

Kamranifakur, SH , (2006), The Prevalence of Domestic Violence Experienced Runaways, social welfare sixth year , No. 22.

Kennedy, David. P., Joan, S. Tucker, Harold D. Green Jr, Daniela Golinelli. \& Brett Ewing. (2012). Unprotected Sex of Homeless Youth: Results from a Multilevel Analysis of individual, Social Network, and Relationship Factors, National Institutes of Health. AIDS Behav. 16(7): 2015-2032.

Lajavardi, S. , (2004), The Relationship Between Attachment Styles and Attitude Toward Substance Abuse at Shahid Beheshti University of Medical Sciences, MSc course in Clinical Psychology, University Rudhen.

Leslie, M. B., Stein, J. A., Rotheram-Borus, M. J. (2002). Sex-Specific Predictors of Suicide Among Runaway Youth, Journal of Clinical child and Adolescent Psychology. 31. 27-40.

Lewis. M. (1991). Child and Adolescent Psychology, A Comprehensive Test Book. London. Kowkab Publisher. 
Jamshidi , B. ; Faridehsadat Hosseini, Narges Arab- Moghaddam (2010), Prediction of girls Running Away by Using the Big Five Personality factor, Iranian Journal of Psychiatry and Clinical Psychology , year XVI , No. 2.

McGaha, J. E. and Leoni, E. L. (1995). Family Violence, Abuse, and Related Family Issues of Incarcerated Delinquents with Alcoholic Parents Compared to Those with Nonalcoholic Parents, Adolescence. 118. 473-482.

Moazzami Goudarzi , B. , J. Ejeie, Seyed Kazem Rasoulzadeh Tabatabai (2001), The Effects Of Training Of Stress Control And Ways Of Coping Skills, psychology, No. 20.

Mohammadi , Z. , (2004), Women's social problems in (1991-2001) , Tehran : Public Relations of Women's Cultural and Social Council.

Momtaz , F., (2002) , Social Deviance Theories And Perspectives, Tehran : Publishing Corporation .

Navabakhsh , M. , MJ ghaedmohammady , (2007), Family Factors And Psychological Effects On Girls Running Away From Home, Applied Psychology , First edition, No. 4 .

Pash Sharifi , H , N. Sharifi , (2004), Research Methods in Behavioural Sciences, Tehran: sokhan.

Qulizadeh zoleikha, Abbas Bakhshypour, J. Babapour Khairuddin , (2007), personality factors, and solving environmental problems affecting 18-12 girls running away from home, Applied Psychology, First edition, No. 4 .

Rabyngtn , Earl ; Weinberg, Martin , (2003), Seven Theoretical Approaches in the Study of Social Issues, translation Rahmatullah sedigh Sarvestani, Tehran : Tehran University Press .

Rasoulzadeh Tabatabai , K. ; Muhammad Ali Basharat, M. Bazyari , (2005) , Comparison of Personality Traits, Social and Economic Conditions of the Runaways and Normal Girls, two- monthly magazine Daneshvar raftar / Shahed University, Year XII , No. 10 .

Ribeiro, M. O. (2008). Street children and their relationship with the police, International Nursing Review. 55. 89-98.

Rosenthal, D., Mallett, S., \& Myers, P. (2006). Why do homeless young people leave home? Australian and New Zealand, Journal of Public Health. 30. 185-281.

Sahin, N; Timor, S; Ergin, A. (2010). Chilhood trauma, type of marriage and self-esteem as correlates of domestic violence in married women in turkey, Journal of Family Violence. 7(25). 661-668.

Saki , M. , Mitra Safa, Hossein Jazayeri et al , (2007), Review of personality and psychological characteristics of runaway women and girls maintained in social crises intervention centers Lorestan , Lorestan University of Medical Sciences Quarterly , ninth edition , No. 1 .

Saliou, V., Fichelle, A., McLoughlin, M., Thauvin, I., \& Lejoyeux, M. (2005). Psychiatric Disorders Among Patients Admitted to a French Medical Emergency Service, General Hospital Psychiatry. 24. 263-268.

Samani, S, (2006), Family Cohesion and Emotional Independence in Runaway Girls , Journal of Psychiatry and Clinical Psychology ( thoughts and behavior ), No. 46 .

Shareh, Hussain , Hamid Agha Mohammadian, (2007), The Relationship Between Identity Bases and Girls Running Away From Home, Iranian Journal of Psychiatry and Clinical Psychology, Year XIII , No. 2.

Shareh , H. , (2008) , The Correlations Between Demographic Variables and Risk of Running Away in Adolescent Girls in Mashhad, mental health concepts, the tenth year, No. 37 .

Shareh, Hussein, Ali Farid, rokhsareh yekke yazdandoust et al , (2006), The Relationship Between Emotional Intelligence and Risk Factors In Adolescent Girls Running Away From Home, social welfare fifth year , No. 21.

Sappington, A. A. (2000). Childhood Abuse as a Possible Focus for Early Intervention into Problems of Violence and Psychopathology, Aggression and Violent Behavior. Vol 4. No 2.

Sharlin S. A. and Mor-Barak M. (1992). Runaway Girls in Distress: motivation, Background, and Personality. Journal of Adolescence. Vol. 27, pp:377-405.

Sherman, S. S., Plitt, S., UL Hassan, S., Cheng, Y., \& Zafar, S. T. (2005). Drug use, street survival, and risk behaviors among street children in Lahore, Pakistan, Journal of Health: Bulletin of New York Academy of Medicine, 82, 113-124.

Spirito, A., \& Esposito-Smythers, C. (2006). Attempted and Completed Suicide in Adolescence, Annual of Clinical Psychology. 2. 237266.

Tehranizadeh, Maryam, K. Rasoulzadeh Tabatabai, P. azad fallah , ( 2005), Comparative study of dysfunctional attitudes in the Runaways and normal girls. welfare, Fifth Year, No. 19.

Tyler, K. A., Cauce, A. M., Whitbeck, L. (2004). Family Risk Factors and Prevalence of Dissociative Symptoms among Homeless and Runaway Youth, Child Abuse and Neglect. 28. 355-366.

Whithback, L. B; Hoyt, D. R \& Ackley, K. A. (1997). Families of Homeless and Runaway Adolescents: A Coomparison of Parent / Caretaker and Adolescent Perspectives on Parenting, Family Violence and Adolescent Conduct. Child Abuse and Neglect. Vol 21. No 6.

Zemmerman, M. A. et al. (1997). A longitudinal study of self-esteem: Emplications for adolescent, Journal of Youth and Adolescent. 26. 117-140.

Zargar, F. , A. Moradi , Saeed Imani (2008), Comparing the Characteristics of Normal and Runaway Women and Girls in Isfahan , thoughts and behavior, third year, No. 10 .

Zamani, Z. ; Susan kebari , Habib aghabakhshy, (2012), The Relationship Between Social Trust and Girls Running Away from Home, social studies, fourth year, No. 4 . 